\title{
C-Arylation reactions catalyzed by CuO-nanoparticles under ligand free conditions
}

Mazaahir Kidwai", Saurav Bhardwaj and Roona Poddar

\section{Full Research Paper}

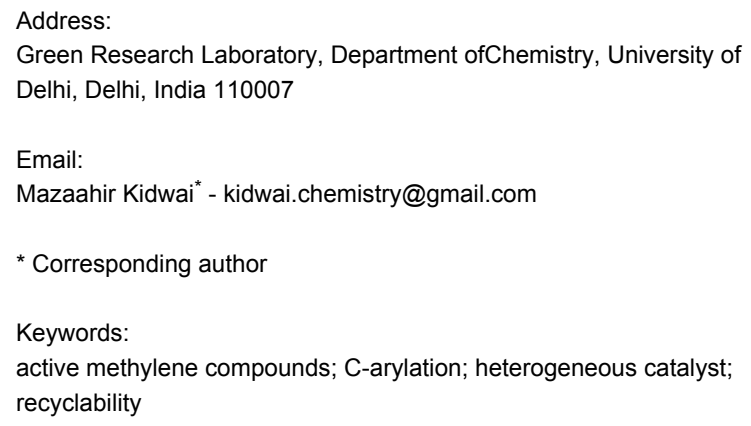

\section{Open Access}

Beilstein Journal of Organic Chemistry 2010, 6, No. 35 doi:10.3762/bjoc.6.35

Received: 04 February 2010

Accepted: 25 March 2010

Published: 15 April 2010

Associate Editor: I. Marek

() 2010 Kidwai et al; licensee Beilstein-Institut.

License and terms: see end of document.

\begin{abstract}
$\mathrm{CuO}$-nanoparticles were found to be an excellent heterogeneous catalyst for C-arylation of active methylene compounds using various aryl halides. The products were obtained in good to excellent yield. The catalyst can be recovered and reused for four cycles with almost no loss in activity.
\end{abstract}

\section{Introduction}

Carbon-carbon $(\mathrm{C}-\mathrm{C})$ bond formation is one of the most important reactions in organic synthesis [1-3]. The resulting compounds formed from $\mathrm{C}-\mathrm{C}$ coupling are valuable synthons in organic synthesis [4-7]. However, C-arylation reactions have not been investigated to the same extent as other $\mathrm{C}-\mathrm{C}$ bond forming reactions.

A great deal of attention has been focused on the development of Pd catalyzed arylation [8-11]. Another important protocol involves arylation of activated methylene compounds mediated by copper salts $[12,13]$. Recently, proline has also been used along with $\mathrm{CuI}$ for C-arylation [14]. But some of the methods suffer from serious drawbacks and limitations, for example, long reaction times $[15,16]$, the high cost of Pd catalysts $[17,18]$ and the need for stoichiometric amounts of copper salts. In add- ition to these problems, the major drawback is that the majority of catalysts cannot be reused [19]. To overcome from these problems, we have investigated a new catalytic system for C-arylation.

Nanocrystalline metal oxides find numerous applications, e.g., as active adsorbents for gases [20], the destruction of hazardous materials [21] and the oxidation of volatile organic compounds [22]. In addition, metal oxide nanoparticles have been used as heterogeneous catalysts for various organic transformations [2328]. The high reactivity of $\mathrm{CuO}$-nanoparticles (CuO-np) is due to the high surface area of nanoparticles combined with unusual reactive morphologies. Moreover, heterogeneous catalysts are easy to separate and can be recycled. This is very beneficial for industrial process in the green chemistry domain. 
In continuation with our research program to explore different methodologies for the synthesis of organic compounds [29,30] and the role of transition metal nanoparticles as catalysts in organic reactions [31-33], we now report the synthesis of 3-arylpentane-2,4-diones and diethyl 2-aryl-malonates using $\mathrm{CuO}$-nanoparticles as a heterogeneous catalyst.

\section{Results and Discussion}

The reaction was carried out several times in order to establish the optimum ratio of reactants. Iodobenzene and acetylacetone were employed as model substrates in a 1:3 ratio. When the iodobenzene $(1 \mathrm{mmol})$ and acetylacetone $(3 \mathrm{mmol})$ were stirred with $\mathrm{Cs}_{2} \mathrm{CO}_{3}(0.5 \mathrm{mmol})$ at $80{ }^{\circ} \mathrm{C}$ in DMSO, in the presence of CuO-nanoparticles (10 mol \%), 3-phenyllpentane-2,4-dione was obtained in $80 \%$ yield (Scheme 1).
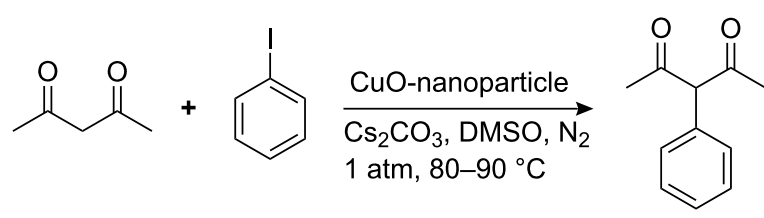

Scheme 1: Synthesis of 3-phenylpentane-2,4-dione using CuO-nanoparticles.

Other copper salts such as $\mathrm{Cu}(\mathrm{OAc})_{2}$ and ordinary $\mathrm{CuO}$ were found to be inferior to $\mathrm{CuO}$-nanoparticles and gave low yields of 3-phenylpentane-2,4-dione. Moreover, Cu-nanoparticles which have been used for O-arylation and S-arylation [34,35], were not effective in the coupling reaction (Table 1).
Table 1: C-arylation reaction catalyzed by different $\mathrm{Cu}$ catalysts ${ }^{\mathrm{a}}$.

\begin{tabular}{lccc} 
Entry & Catalyst & Time $(\mathrm{h})$ & Yield $^{\mathrm{b}}(\%)$ \\
\hline 1 & $\mathrm{Cu}(\mathrm{OAc})_{2}$ & 10 & 20 \\
2 & $\mathrm{Cu}-\mathrm{np}$ & 10 & 10 \\
3 & $\mathrm{CuO}$ & 10 & 24 \\
4 & $\mathrm{CuO}-\mathrm{np}$ & 8 & 80 \\
\hline
\end{tabular}

aReaction conditions: acetylacetone $(3 \mathrm{mmol})$, iodobenzene $(1 \mathrm{mmol})$, $10 \mathrm{~mol} \%$ of catalyst, $\mathrm{Cs}_{2} \mathrm{CO}_{3}(0.5 \mathrm{mmol}), \mathrm{DMSO}$; temperature $80^{\circ} \mathrm{C}$; $\mathrm{N}_{2} ; 1$ atm.

blsolated and optimized yield.

In addition, catalytic activity of $\mathrm{CuO}$-nanoparticles was evident since no product was formed in its absence. The increased catalytic activity of $\mathrm{CuO}$-nanoparticles over the commercially available bulk $\mathrm{CuO}$ may be attributed to the higher surface area of CuO-nanoparticles. This is thought to be due to morphological differences which have been shown in the TEM image. The number of reactive sites on the surface is small in the case of larger crystallites and considerably greater in the case of smaller crystallites (Figure 1).

To investigate further the surface morphology of CuO-nanoparticles, powder XRD and TEM images were taken. Figure 1 shows the XRD pattern of CuO-nanoparticles in which diffraction peaks can be indexed to a monoclinic structure. The intense diffraction peak at an angle 38.4 shows index plane (111) which contains more basic sites with higher density as compared to bulk $\mathrm{CuO}$.
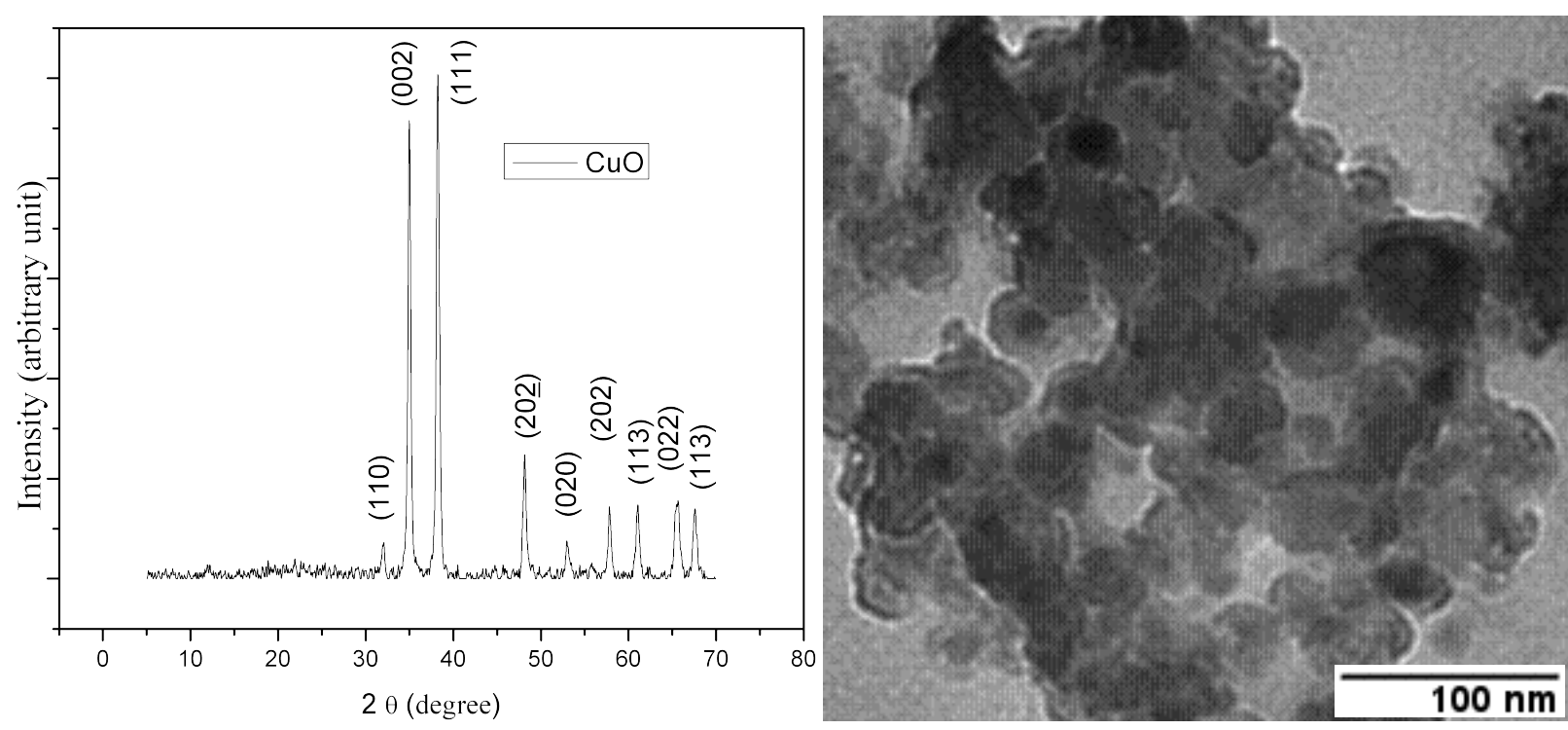

Figure 1: Powder X-ray diffraction pattern and TEM image of nano $\mathrm{CuO}$ (fresh). 
During optimization of reaction conditions, the model reaction was carried out in different solvents. It was found that DMSO was the most effective solvent compared to the other solvents used as shown in Table 2. This is not surprising in view of the fact that the reaction intermediate is a carbanion and therefore will have a greater stability in a polar solvent.

Table 2: CuO-nanoparticles catalyzed coupling reaction of acetylacetone and iodobenzene in various solvents ${ }^{a}$.

\begin{tabular}{lccc} 
Entry & Solvent & Time $(\mathrm{h})$ & Yield $^{\mathrm{b}}(\%)$ \\
\hline 1 & DMSO & 8 & 80 \\
2 & Toluene & 15 & 8 \\
3 & THF & 15 & 12 \\
4 & Acetonitrile & 15 & 32 \\
\hline
\end{tabular}

aReaction conditions: acetylacetone ( $3 \mathrm{mmol})$, iodobenzene (1 mmol), $10 \mathrm{~mol} \% \mathrm{CuO}$-nanoparticles, $\mathrm{Cs}_{2} \mathrm{CO}_{3}(0.5 \mathrm{mmol})$, solvent; temperature $80^{\circ} \mathrm{C} ; \mathrm{N}_{2} ; 1 \mathrm{~atm}$.

b/solated and optimized yield.

Moreover, the advantage of the nanoparticles is that, unlike other catalysts, their use is not restricted by their solubility, as the nanoparticles can be dispersed in the desired solvent by agitation or slight sonication.

When an equimolar mixture of chlorobenzene and iodobenzene was treated with acetylacetone under similar reaction conditions, the chlorobenzene was largely unreactive. This shows that the reaction is highly selective towards the halogen present in the aryl halide (Scheme 2).

To study the scope of this procedure, acetylacetone was reacted with various aryl halides and gave the corresponding products in $78-83 \%$ yield. It was observed that aryl halides having electron withdrawing groups showed greater reactivity and gave good yield of products compared to aryl halides having elec-

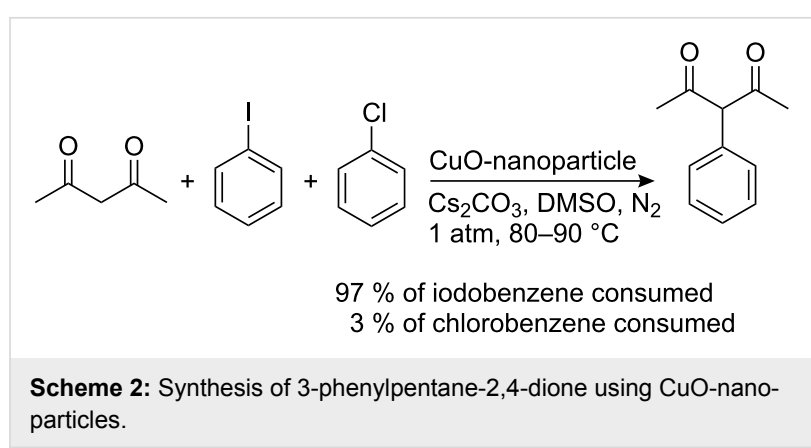

tron donating groups. All these results are summarized in Table 3 .

The above results encouraged us to investigate further reactions. Under similar reaction conditions, diethyl malonate was treated with iodobenzene to give the desired product in $78 \%$ yield (Scheme 3). The reaction was then repeated with a variety of aryl halides. The results are summarized in Table 4.

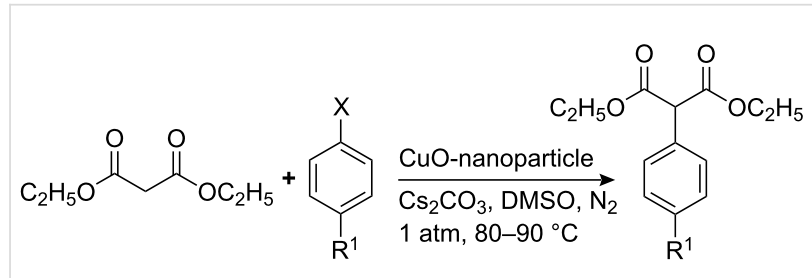

Scheme 3: Synthesis of diethyl 2-aryl-malonate using CuO-nanoparticles.

The observed decrease in reactivity in the order $p$-nitroiodobenzene $>$ iodobenzene $>p$-methyliodobenzene $>1$-iodo-4-methoxybenzene suggests that the reaction proceeds by oxidative addition followed by reductive elimination. In addition to this, the order of reactivity suggests that aryl halides having electron withdrawing groups stabilize the transition state which corres-

\begin{tabular}{|c|c|c|c|c|}
\hline Entry & Aryl halide & Product & Time $(\mathrm{h})$ & Yield $^{\mathrm{b}}(\%)$ \\
\hline 1 & iodobenzene & 3-phenylpentane-2,4-dione & 8 & 80 \\
\hline 2 & bromobenzene & 3-phenylpentane-2,4-dione & 10 & 79 \\
\hline 3 & p-nitroiodobenzene & 3-(4-nitrophenyl)-pentane-2,4-dione & 6 & 83 \\
\hline 4 & p-methyliodobenzene & 3-p-tolylpentane-2,4-dione & 10 & 78 \\
\hline 5 & $m$-trifluoromethyliodobenzene & 3-(3-trifluromethyl-phenyl)-pentane-2,4-dione & 7 & 81 \\
\hline 6 & 1-iodo-2-methylbenzene & 3-o-tolyl-pentane-2,4-dione & 11 & 76 \\
\hline 7 & 1-iodo-4-methoxybenzene & 3-(4-methoxy-phenyl)-pentane-2,4-dione & 12 & 75 \\
\hline
\end{tabular}

aReaction conditions: acetylacetone $(3 \mathrm{mmol})$, aryl halide $(1 \mathrm{mmol}), 10 \mathrm{~mol} \%$ CuO-nanoparticles, $\mathrm{Cs}_{2} \mathrm{CO}_{3}(0.5 \mathrm{mmol}), \mathrm{DMSO}$; temperature $80{ }^{\circ} \mathrm{C}$; $\mathrm{N}_{2} ; 1$ atm.

${ }^{\mathrm{b}}$ Isolated and optimized yields. 


\begin{tabular}{|c|c|c|c|c|}
\hline Entry & Aryl halide & Product & Time (h) & Yield $^{b}(\%)$ \\
\hline 1 & iodobenzene & 2-phenylmalonic acid diethylester & 9 & 78 \\
\hline 2 & bromobenzene & 2-phenylmalonic acid diethylester & 11 & 76 \\
\hline 3 & p-nitroiodobenzene & 2-(4-nitrophenyl)-malonic acid diethylester & 6 & 81 \\
\hline 4 & p-methyliodobenzene & 2-p-tolylmalonic acid diethylester & 12 & 76 \\
\hline 5 & $m$-trifluoromethyliodobenzene & 2-(3-trifluromethyl-phenyl)-malonic acid diethylester & 7 & 80 \\
\hline 6 & 1-iodo-2-methylbenzene & 2-o-tolylmalonic acid diethylester & 13 & 75 \\
\hline 7 & 1-iodo-4-methoxybenzene & 3-(4-methoxy-phenyl)-malonic acid diethylether & 14 & 74 \\
\hline
\end{tabular}

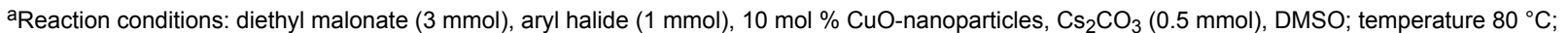
$\mathrm{N}_{2} ; 1$ atm.

blsolated and optimized yields.

ponds to good yields with a short reaction time in comparison to aryl halides having electron donating groups (Figure 2).

The reaction was then carried out with recycled catalyst. The $\mathrm{CuO}$-nanoparticles were recovered by centrifugation of the reaction mixture and washed thoroughly with ethyl acetate. The resulting nanoparticles could be reused for several cycles without any significant loss of activity. In our study, we used same nanoparticles three times and the results are summarized below (Table 5). The TEM and XRD analysis of recycled CuOnanoparticles, after the fourth run showed that particles are identical in shape and size, hence $\mathrm{CuO}$-nanoparticles are unchanged during the reaction (Figure 3).

\section{Conclusion}

An efficient, facile and economical method for synthesis of 3-arylpentane-2,4-diones (Table 3) and diethyl 2-aryl-malon-

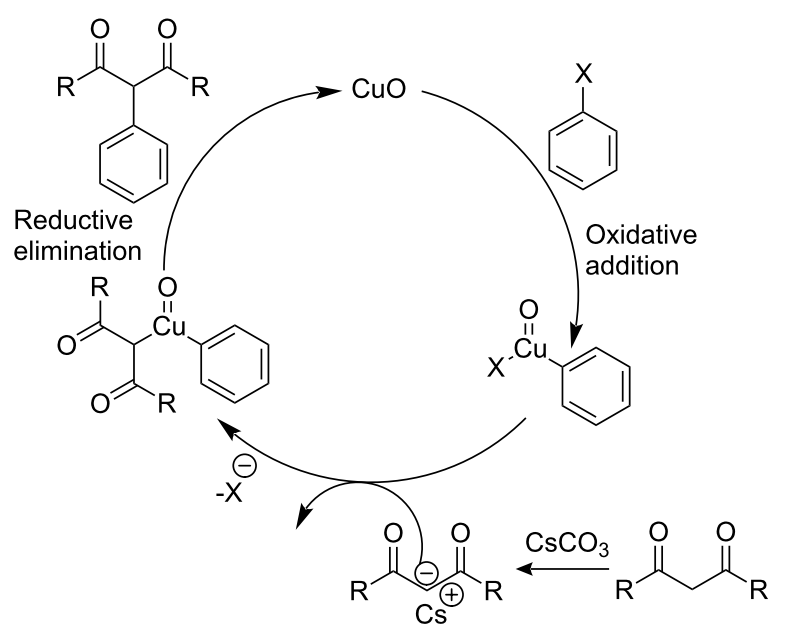

Figure 2: Proposed reaction pathway for the CuO-nanoparticles catalyzed $\mathrm{C}-\mathrm{C}$ coupling reaction.
Table 5: Recycle studies of nano-CuO for C-arylation reaction ${ }^{\mathrm{a}}$.

$\begin{array}{lll}\text { Run } & \text { Time }(\mathrm{h}) \quad \text { Yield }^{\mathrm{b}}(\%)\end{array}$

\begin{tabular}{lll}
\hline 1 & 8 & 80 \\
2 & 8 & 78 \\
3 & 8 & 77 \\
4 & 8 & 76 \\
\hline
\end{tabular}

a Reaction conditions: acetylacetone $(3 \mathrm{mmol})$, iodobenzene $(1 \mathrm{mmol})$, $10 \mathrm{~mol} \% \mathrm{CuO}-$ nanoparticles, $\mathrm{Cs}_{2} \mathrm{CO}_{3}(0.5 \mathrm{mmol})$, DMSO; temperature $80^{\circ} \mathrm{C} ; \mathrm{N}_{2} ; 1$ atm.

blsolated and optimized yields.

ates (Table 4) has been developed using $\mathrm{CuO}$-nanoparticles as the catalyst. The products were obtained in moderate to good yields and the catalyst can be recycled up to four cycles with almost consistent activity. The present protocol represents a simple and remarkably active catalytic system to catalyze Ullmann-type $\mathrm{C}-\mathrm{C}$ bond formation, which potentially offers an efficient protocol for accessing a variety of $\alpha$-arylated dicarbonyl compounds.

\section{Experimental General}

The materials were purchased from Sigma-Aldrich and Merck and were used without further purification. Mass spectra were recorded in a TOF-mass spectrometer model no. KC455. ${ }^{1} \mathrm{H}$ NMR and ${ }^{13} \mathrm{C}$ NMR spectra were recorded on a Bruker spectrospin at $300 \mathrm{MHz}$ and $75 \mathrm{MHz}$, respectively. All ${ }^{1} \mathrm{H}$ NMR and ${ }^{13} \mathrm{C}$ NMR spectra were run in $\mathrm{CDCl}_{3}$ and chemical shifts are expressed as ppm relative to internal $\mathrm{Me}_{4} \mathrm{Si}$. Elemental analyses were performed using Heraeus CHN-Rapid Analyzer. Powder $X$-ray diffraction measurements were carried out on a Bruker D8 Discover HR-XRD instrument using $\mathrm{Cu} \mathrm{K} \alpha$ radiation $(\lambda=$ $1.54184 \AA$ ). 


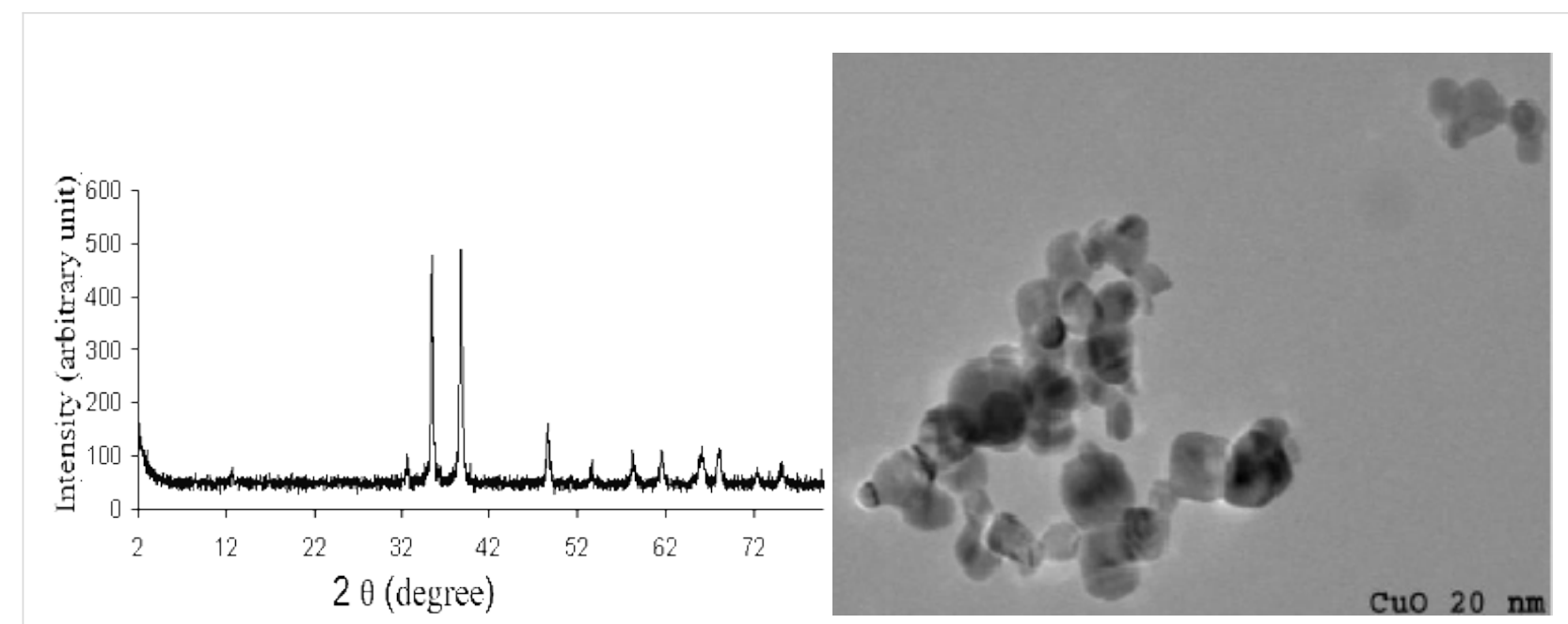

Figure 3: Powder X-ray diffraction pattern and TEM image of recycled CuO-nanoparticles.

\section{Experimental Section}

CuO-nanoparticles (10 mol \%) were added to the mixture of iodobenzene $(1 \mathrm{mmol})$, acetylactone $(3 \mathrm{mmol})$ and $(0.5 \mathrm{mmol})$ of $\mathrm{Cs}_{2} \mathrm{CO}_{3}$ in DMSO $(2 \mathrm{ml})$ under nitrogen atmosphere. The resulting reaction mixture was stirred at $80{ }^{\circ} \mathrm{C}$ for $8 \mathrm{~h}$. Progress of the reaction was continuously monitored by TLC. After completion of reaction, the catalyst was recovered by centrifugation. The nanoparticles, were first washed with distilled methanol to remove some of the $\mathrm{Cs}_{2} \mathrm{CO}_{3}$, then several times with ethyl acetate and dried in an oven overnight at $150{ }^{\circ} \mathrm{C}$. The filtrate was poured into $1 \mathrm{~N} \mathrm{HCl}$ and extracted with EtOAc. The combined organic layers were washed with brine, dried over anhydrous $\mathrm{Na}_{2} \mathrm{SO}_{4}$ and concentrated at reduced pressure. The residue was chromatographed to afford pure 3-phenyl-2,4pentadione (Entry 1, Table 3). From the spectral data it was observed that some products show 1,3-keto-enol tautomerism. The structures of all the products were unambiguously established on the basis of their spectral properties $\left({ }^{1} \mathrm{H}\right.$ NMR, MS and ${ }^{13} \mathrm{C} \mathrm{NMR}$ ).

\section{Supporting Information}

\section{Supporting Information File 1}

Typical procedure and characterization data of prepared compounds

[http://www.beilstein-journals.org/bjoc/content/ supplementary/1860-5397-6-35-S1.pdf]

\section{Acknowledgements}

Saurav Bhardwaj and Roona Poddar thank CSIR, New Delhi for providing a fellowship.

\section{References}

1. Ren, T. Chem. Rev. 2008, 108, 4185-4207. doi:10.1021/cr8002592

2. Hart, D. J. Science 1984, 223, 883-887. doi:10.1126/science.223.4639.883

3. Iwama, T.; Rawal, V. H. Org. Lett. 2006, 8, 5725-5728. doi:10.1021/ol062093g

4. Ramthoul, Y. K.; Chartrand, A. Org. Lett. 2007, 9, 1029-1032. doi:10.1021/ol063057k

5. Masselot, D.; Charmant, J. P. H.; Gallagher, T. J. Am. Chem. Soc. 2006, 128, 694-695. doi:10.1021/ja056964d

6. Wu, J. Y.; Nie, L.; Luo, J.; Dai, W.-M. Synlett 2007, 2728-2732. doi:10.1055/s-2007-991053

7. Kamikawa, K.; Takemoto, I.; Takemoto, S.; Matsuzaka, H. J. Org. Chem. 2007, 72, 7406-7408. doi:10.1021/jo0711586

8. Wright, J. B. J. Org. Chem. 1964, 29, 1905-1909. doi:10.1021/jo01030a059

9. Beare, N. A.; Hartwig, J. F. J. Org. Chem. 2002, 67, 541-555. doi:10.1021/jo016226h

10. You, J.; Verkade, J. G. Angew. Chem. 2003, 42, 5051-5053. doi:10.1002/anie.200351954

11. Thathagar, M. B.; Rothenberg, G. Org. Biomol. Chem. 2006, 4, 111-115. doi:10.1039/b513450a

12. Thathagar, M. B.; Beckers, J.; Rothenberg, G. Green Chem. 2004, 6, 215-218. doi:10.1039/b401586j

13. Suzuki, H.; Kobayashi, T.; Osuka, A. Chem. Lett. 1983, 12, 589-590. doi:10.1246/cl.1983.589

14. Setsune, J.-I.; Matsukawa, K.; Wakemoto, H.; Kitao, T. Chem. Lett. 1981, 10, 367-370. doi:10.1246/cl.1981.367

15. Jiang, Y.; Wu, N.; Wu, H.; He, M. Synlett 2005, 2731-2734. doi:10.1055/s-2005-918921

16. Yip, S. F.; Cheung, H. Y.; Zhou, Z.; Kwong, F. Y. Org. Lett. 2007, 9 , 3469-3472. doi:10.1021/ol701473p

17. Fox, J. M.; Huang, X.; Chieffi, A.; Buchwald, S. L. J. Am. Chem. Soc. 2000, 122, 1360-1370. doi:10.1021/ja993912d

18. Culkin, D. A.; Hartwig, J. F. J. Am. Chem. Soc. 2001, 123, 5816-5817. doi:10.1021/ja015732I

19. Li, P.; Wang, L.; Li, H. Tetrahedron 2005, 61, 8633-8640. doi:10.1016/j.tet.2005.07.013 
20. Okuro, K.; Furuune, M.; Miura, M.; Nomura, M. J. Org. Chem. 1993, 58, 7606-7607. doi:10.1021/jo00078a053

21. Lucas, E.; Decker, S.; Khaleel, A.; Seitz, A.; Fultz, S.; Ponce, A.; Li, W.; Carnes, C.; Klabunde, K. J. Chem.-Eur. J. 2001, 7, 2505-2510. doi:10.1002/1521-3765(20010618)7:12<2505::AID-CHEM25050>3.0.C $\mathrm{O} ; 2-\mathrm{R}$

22. Jiang, Y.; Decker, S.; Mohs, C.; Klabunde, K. J. J. Catal. 1998, 180, 24-35. doi:10.1006/jcat.1998.2257

23. Larsson, P.-O.; Andersson, A. J. Catal. 1998, 179, 72-89. doi:10.1006/jcat.1998.2198

24. Rout, L.; Jammi, S.; Punniyamurthy, T. Org. Lett. 2007, 9, 3397-3399. doi:10.1021/ol0713887

25. Kantam, M. L.; Laha, S.; Yadav, J.; Bhargava, S. Tetrahedron Lett. 2008, 49, 3083-3086. doi:10.1016/j.tetlet.2008.03.053

26. Chikán, V.; Molnár, Á.; Belázsik, K. J. Catal. 1999, 184, 134-143. doi:10.1006/jcat.1999.2437

27. Kantam, M. L.; Yadav, J.; Laha, S.; Sreedhar, B.; Jha, S. Adv. Synth. Catal. 2007, 349, 1938-1942. doi:10.1002/adsc.200600483

28. Rout, L.; Sen, T. K.; Punniyamurthy, T. Angew. Chem., Int. Ed. 2007, 46, 5583-5586. doi:10.1002/anie.200701282

29. Kidwai, M.; Poddar, R.; Mothsra, P. Beil. J. Org. Chem. 2009, 5, No. 10. doi:10.3762/bjoc.5.10

30. Kidwai, M.; Poddar, R.; Diwaniyan, S.; Kuhad, R. C. Adv. Synth. Catal. 2009, 351, 589-595. doi:10.1002/adsc.200800611

31. Kidwai, M.; Bhatnagar, D.; Mishra, N. K.; Bansal, V. Catal. Commun. 2008, 9, 2547-2549. doi:10.1016/j.catcom.2008.07.010

32. Kidwai, M.; Bhardwaj, S.; Mishra, N. K.; Bansal, V.; Kumar, A.; Mozumdar, S. Catal. Commun. 2009, 10, 1514-1517. doi:10.1016/j.catcom.2009.04.006

33. Kidwai, M.; Bansal, V.; Kumar, A.; Mozumdar, S. Green Chem. 2007, 9, 742-745. doi:10.1039/b702287e

34. Kidwai, M.; Mishra, N. K.; Bansal, V.; Kumar, A.; Mozumdar, S. Tetrahedron Lett. 2007, 48, 8883-8887. doi:10.1016/j.tetlet.2007.10.050

35. Gonzalez-Arellano, C.; Luque, G.; Macquarrie, D. J. Chem. Commun. 2009, 1410-1412. doi:10.1039/b818767c

\section{License and Terms}

This is an Open Access article under the terms of the Creative Commons Attribution License (http://creativecommons.org/licenses/by/2.0), which permits unrestricted use, distribution, and reproduction in any medium, provided the original work is properly cited.

The license is subject to the Beilstein Journal of Organic Chemistry terms and conditions: (http://www.beilstein-journals.org/bjoc)

The definitive version of this article is the electronic one which can be found at: doi:10.3762/bjoc. 6.35 